\title{
PROFIL ABSES SUBMANDIBULA \\ DI BAGIAN BEDAH RS Prof. Dr. R. D. KANDO MANADO \\ PERIODE JUNI 2009 SAMPAI JULI 2012
}

\author{
${ }^{1}$ Inggrid Hesly \\ ${ }^{2}$ Nico Lumintang \\ ${ }^{2}$ Hilman Limpeleh \\ ${ }^{1}$ Kandidat Skripsi Fakultas Kedokteran Universitas Sam Ratulangi Manado \\ ${ }^{2}$ Bagian Bedah BLU RSU Prof. dr. R.D. Kandou Manado
}

\begin{abstract}
Abstrak: Abses submandibula adalah suatu peradangan yang disertai pembentukan pus pada daerah submandibula. Abses submandibula menempati urutan tertinggi dari seluruh abses leher dalam. 70-85 \% kasus yang disebabkan oleh infeksi gigi merupakan kasus terbanyak, selebihnya disebabkan oleh sialadenitis, limfadenitis, laserasi dinding mulut atau fraktur mandibula. Tujuan penelitian ini untuk mengetahui profil kasus abses submandibula

Metode penelitian yang digunakan bersifat retrospektif deskriptif. Data diambil dari rekam medis semua pasien abses submandibula di bagian bedah BLU/RSUP Prof. dr. R.D. Kandou Manado selama tiga tahun terakhir dari Juni 2009 sampai Juli 2013.

Berdasarkan data dari 39 pasien abses submandibula ditemukan 21 (53\%) pasien laki-laki dan 18 (47\%) pasien perempuan. Pada kelompok umur di atas 50 tahun terdapat 13 pasien, kelompok umur 41-50 tahun sebanyak 10 pasien, 31-40 tahun sebanyak 2 pasien, 21-30 tahun sebanyak 7 pasien, 11-20 tahun sebanyak 4 pasien, 0-10 tahun sebanyak 3 pasien.

Berdasarkan dari hasil penelitian didapakan data mengenai abses submandibula yaitu pasien laki-laki lebih banyak dari pasien perempuan. Kelompok umur di atas 50 tahun merupakan kelompok umur terbanyak.
\end{abstract}

Kata Kunci: Abses Submandibula

Abstract: Submandibular abscess is an inflammation with pus formation at submandibular region. submandibular abscess take the highest incidence rate of all types of neck abscesses. most of cases which caused by teeth infection at range 70-85\%, the rest are caused by sialadenitis, lymphadenitis, mouth wall laceration or fracture of the mandible. Aim of this study was to determine the profile of the submandibular abscess cases .

This was descriptive retrospective observational research. Data were obtained from medical record from department of surgery BLU/RSUP Prof. dr. R. D. Kandou Manado for last three years from June 2009 to July 2012.

Based on 39 cases of submandibula abscess has found 21 male ( $53 \%$ ) and 18 female patients ( $47 \%$ ). In the age category over 50 years, there were 13 patient, 41-50 years there were 10 patients, 31-40 years age group by 2 patients, 21-30 years there were 7 patients , 11-20 years there were 4 patients , 0-1 years there were 3 patients.

Result from this research is numbers male patient more than female patient, and the most patient is on over 50 years age category

Keywords : Submandibular Abscess 


\section{LATAR BELAKANG}

Abses adalah kumpulan pus yang terletak dalam satu kantung yang terbentuk dalam jaringan yang disebabkan oleh suatu proses infeksi oleh bakteri, parasit atau benda asing lainnya. Abses merupakan reaksi pertahanan yang bertujuan mencegah agen-agen infeksi menyebar ke bagian tubuh lainnya. Pus itu sendiri merupakan suatu kumpulan sel-sel jaringan lokal yang mati, sel-sel darah putih, organisme penyebab infeksi atau benda-benda asing dan racun yang dihasilkan oleh organisme dan sel-sel darah., ${ }^{1,2,3}$

Abses submandibula adalah suatu peradangan yang disertai pembentukan pus pada daerah submandibula. Keadaan ini merupakan salah satu infeksi pada leher bagian dalam (deep neck infection). Pada umumnya sumber infeksi pada ruang submandibula berasal dari proses infeksi dari gigi, dasar mulut, faring, kelenjar limfe submandibula. Mungkin juga kelanjutan infeksi dari ruang leher dalam lain.

Angka kejadian Abses submandibula berada di bawah abses peritonsil dan retrofaring. Namun dewasa ini, angka kejadiannya menduduki urutan tertinggi dari seluruh abses leher dalam. 70 - 85\% dari kasus disebabkan oleh infeksi dari gigi, selebihnya karena sialadenitis, limfadenitis, laserasi dinding mulut atau fraktur mandibula. Selain itu, angka kejadian juga ditemukan lebih tinggi pada daerah dengan fasilitas kesehatan yang kurang lengkap. ${ }^{3}$

Pada kasus infeksi leher dalam rentang usia dari umur 1-81 tahun, laki-laki sebanyak $78 \%$ dan perempuan $22 \%{ }^{7}$. Infeksi peritonsil paling banyak ditemukan, yaitu 72 kasus, diikuti oleh parafaring 8 kasus, submandibula, sublingual dan submaksila masing-masing 7 kasus dan retrofaring 1 kasus. kasus infeksi leher dalam sebanyak 185 kasus. Abses submandibula $(15,7 \%)$ merupakan kasus terbanyak ke dua setelah abses parafaring $(38,4)$, diikuti oleh Ludwig's angina (12,4\%), parotis (7\%) dan retrofaring (5,9\%). kasus abses leher dalam yang diteliti April 2001 sampai Oktober 2006 mendapatkan perbandingan antara lakilaki dan perempuan 3:2. Lokasi abses lebih dari satu ruang potensial 29\%. Abses submandibula $35 \%$, parafaring $20 \%$, mastikator $13 \%$, peritonsil $9 \%$, sublingual $7 \%$, parotis $3 \%$, infra hyoid $26 \%$, retrofaring $13 \%$, ruang karotis $11 \%{ }^{6}$

Abses submandibula sudah semakin jarang dijumpai ${ }^{1,4}$ Hal ini disebabkan penggunaan antibiotik yang luas dan kesehatan mulut yang meningkat. Disamping insisi drainase abses yang optimal, pemberian antibiotik diperlukan untuk terapi yang adekuat. Walaupun demikian, angka morbiditas dari komplikasi yang timbul akibat Abses Submandibula masih cukup tinggi sehingga diagnosis dan penanganan yang cepat dan tepat sangat dibutuhkan. ${ }^{4}$

Sehubungan dengan hal-hal yang telah diuraikan diatas, maka penulis tertarik untuk melakukan penelitian secara khusus, guna mengetahui jumlah kasus kejadian Abses submandibula dibagian Bedah RSU prof.DR. R. D. Kandou Manado.

\section{METODE PENELITIAN}

Metode penelitian yang digunakan bersifat retrospektif destriktif melalui pengambilan data, analisis dan evaluasi Abses Submandibula yang dirawat di bagian bedah Rumah Sakit Umum Prof. DR. R. D. Kandou Manado, selama 3 tahun terakhir dari Juni 2009 sampai Juli 2012. Data diambil dari catatan medik pasien Abses submandibula di bagian bedah Rumah Sakit Umum Prof. DR. R.D. Kandou Manado, periode Juni 2009 sampai Juli 2012.

\section{HASIL PENELITIAN}

Dari hasil penelitian yang dilakukan di bagian bedah Rumah Sakit Umum Prof. dr. R. D. Kandou Manado periode 1 Juni 2009 sampai 31 Juli 2012, didapat 39 kasus dengan hasil sebagai berikut. 
1. Kategori jenis kelamin

Tabel 1. Distribusi frekuensi jenis kelamin

\begin{tabular}{lll}
\hline Jenis Kelamin & Frekuensi & Persentase (\%) \\
\hline Laki-laki & $\mathbf{2 1}$ & $\mathbf{5 3}$ \\
Perempuan & $\mathbf{1 8}$ & $\mathbf{4 7}$ \\
\hline Total & $\mathbf{3 9}$ & $\mathbf{1 0 0}$
\end{tabular}

Dalam tabel 1, terdapat frekuensi jenis pria sebanyak 21 penderita (53\%) sedangkan wanita hanya sebanyak 18 penderita (47\%).

2. Kategori umur

Tabel 2. Distribusi frekuensi umur

\begin{tabular}{|c|c|c|}
\hline $\begin{array}{l}\text { KELOMPOK } \\
\text { (Tahun) }\end{array}$ & UMUR JUMLAH (orang) & PRESENTASI (\%) \\
\hline $0-10$ & 3 & 8 \\
\hline $11-20$ & 4 & 10 \\
\hline $21-30$ & 7 & 18 \\
\hline $31-40$ & 2 & 5 \\
\hline $41-50$ & 10 & 26 \\
\hline$>50$ & 13 & 33 \\
\hline TOTAL & 39 & 100 \\
\hline
\end{tabular}

Dalam tabel 2, didapatkan penderita pada kelompok umur $>50$ tahun terdapat sebanyak 13 penderita atau sebesar 33\% dari keseluruhan penderita, kelompok umur 41-50 tahun yaitu sebanyak 10 orang penderita atau sebanyak 26\%, kelompok umur 21-30 tahun yaitu sebanyak 7 orang penderita atau sebanyak 18\%, kelompok umur 11-20 tahun yaitu sebanyak 4 orang penderita atau sebanyak 10\%, kelompok umur 0-1 tahun yaitu sebanyak 3 orang penderita atau sebanyak 8\%, kelompok umur 31-40 tahun yaitu sebanyak 2 orang penderita atau sebanyak 5\%.

3. Kategori perawatan

Tabel 3. Distribusi frekuensi kategori perawatan

\begin{tabular}{lll}
\hline PERAWATAN & JUMLAH & PRESENTASE(\%) \\
\hline RAWAT INAP & $\mathbf{2 4}$ & $\mathbf{6 2}$ \\
RAWAT JALAN & $\mathbf{1 5}$ & $\mathbf{3 8}$ \\
\hline TOTAL & $\mathbf{3 9}$ & $\mathbf{1 0 0}$ \\
\hline
\end{tabular}

Dalam tabel 3, didapatkan bahwa perawatan pada Abses submandibula yaitu Rawat Inap sebanyak 24 orang penderita (62\%). Rawat Jalan 15 orang penderita (38\%).

4. Kategori tindakan yang diberikan

Tabel 4. Distribusi frekuensi menurut tindakan

\begin{tabular}{lll}
\hline TINDAKAN & JUMLAH & PRESENTASE(\%) \\
\hline NON OPERATIF & $\mathbf{2 2}$ & $\mathbf{5 6}$ \\
OPERATIF & $\mathbf{1 7}$ & $\mathbf{4 4}$ \\
\hline TOTAL & $\mathbf{3 9}$ & $\mathbf{1 0 0}$ \\
\hline
\end{tabular}

Dalam tabel 4, didapatkan bahwa tindakan pada Abses Submandibula yaitu tindakan non operatif sebanyak 22 orang penderita (56\%) dan kemudian Tindakan Operatif 17 orang penderita (44\%). 


\section{PEMBAHASAN}

Sesuai dengan hasil penelitian secara retrospektif dibagian Rekam Medik RSU prof. DR. R. D. Kandaou Manado, didapati jumlah penderita Abses Submandibula yang di bagian poli bedah, IRD Bedah dan Irina A Rumah Sakit Umum Prof. DR. R.D. Kandou Manado, pada periode Juni 2009 sampai Juli 2012 adalah 39 orang.

Diantara penderita-penderita Abses Submandibula didapatkan bahwa mayoritas penderita Abses Submandibula adalah pria dengan presentasi 53\% dibandingkan dengan wanita yang hanya mencapai $43 \%$. Hasil ini tidak jauh beda dengan pernyataan dari Huang T, chen T, Rong P, Tseng F, Yeah T, Shyang C. Deep neck infection: analysis of 18 cases, yang menyatakan bahwa kasus tersering terjadi pada pria dibanding wanita dengan perbandingan 3:2. ${ }^{6}$ Dari hasil penelitian diatas maka dapat disimpulkan bahwa abses submandibula dapat menyerang pria maupun wanita.

Selain pada pria presentasi penderita Abses Submandibula terbanyak juga terdapat pada kelompok umur $>50$ tahun mencapai 33\%. Didapatkan dari beberapa keterangan pasien yang ditulis dalam rekam medik penyebab timbulnya abses tersebut berasal dari infeksi gigi. Oleh karena disaat usia muda pasien kurang menjaga kebersihan gigi sehingga berjalan lanjut usia lebih rentang timbulnya infeksi gigi tersebut yang menyebakan timbulnya abses. Berdasarkan penelitan Abses submandibula ini didapatkan juga pada anak-anak dengan usia termuda 1 tahun dan yang tertua pada umur 70 tahun,oleh karena itu tidak ada batasan umur pada abses submandibula, seperti yang diungkapkan oleh Sakaguchi $M$, Sato S, Ishiyama T, Katsuno T, Taguchi K. characterization and management of deep neck infection. J. Oral Maxillofac Surg 1997;26:131-134 bahwa Abses Submandibula dapat ditemui dari umur 1-81 tahun, Tidak ada batasan umur untuk abses submandibula ini.

Tabel 3 menunjukkan perawatan pasien-pasien Abses Submandibula di Bagian Bedah Rumah Sakit Umum Prof. DR. R.D. Kandou Manado periode Juni 2009 sampai Juli 2012 yang paling sering yaitu perawatan Rawat Inap sebanyak 24 orang penderita (62\%) sedangkan Rawat Jalan 15 orang pnderita (38\%), dimana pasien dengan perawatan rawat inap mendapat tindakan non operatif maupun operatif. Tindakan non operatif yang diberikan kepada pasien berupa antibiotik antara lain Ceftriaxone, Metronidazole, Klindamisin dll. ${ }^{1,2,6,7,8}$ Sedangkan pada tindakan operatif yaitu insisi drainase., ${ }^{2,5,1}$

Dari hasil penelitian menujukkan bahwa tindakan yang paling sering dilakukan pada pasien yaitu tindakan non operatif sebanyak 22 orang penderita (56\%) sedangkan tindakan operatif sebanyak 17 orang penderita (44\%). Data diatas menunjukkan bahwa pasien dengan Abses submandibula lebih banyak mendapat tindakan non operatif berupa pemberian antibiotik dari pada tindakan insisi drainase. Hal ini memungkinkan bahwa penderita lebih cepat menangani abses, sebelum abses ini lebih luas atau terjadinya komplikasi, pasien dengan cepat datang berobat sehingga penanganan dengan antibiotik cukup untuk mencegah terjadinya abses yang lebih luas dan tidak dilakukan insisi. Seperti penelitian yang dilakukan oleh Ariji Y, Gotoh M, Kimura Y, Naitoh K, Kurita K, Natsume N, et al. Ondotogenic infection pathway to the submandibular space: Int. J. Oral Maxillofac Surg. 2002;31:165-9, bahwa semakin berkembangnya antibiotik secara luas dan kesehatan mulut yang meningkat yang menyebabkan berkurangnya tindakan insisi drainase, selain itu pemberian antibiotik diperlukan untuk terapi yang adekuat dalam pencegahan agar tidak terjadinya komplikasi.

Dalam penelitian ini tidak ada kelengkapan data mengenai kultur penyebab dari kasus Abses Submandibula di Bagian Bedah Rumah Sakit Umum Prof. dr. R.D. Kandou Manado, pada periode Juni 2009 sampai Juli 2012. Hal ini mungkin disebabkan karena ketidaksanggupan dana dari pasien untuk pengambilan kultur, ketidaktahuan pasien akan pentingnya pengambilan kultur, pencatatan rekam medik yang kurang lengkap atau kelalaian tim medis yang tidak menyarankan pasien untuk pengambilan kultur kuman penyabab dari Abses submandibula ini. Namun berdasarkan penelitian yang sebelumnya telah dilakukan 
oleh Huang T, chen T, Rong P, Tseng F, Yeah T, Shyang C. Deep neck infection: analysis of 18 cases mengatakan bahwa kultur penyebab dari Abses Submandibula disebabkan oleh campuran berbagai kuman, baik kuman aerob, anaerob, maupun fakultatif anaerob. Kuman aerob yang sering ditemukan adalah Stafilokokus, Streptococcus sp, Haemofilusinfluenza, Streptococcus Pneumonia, Moraxtella catarrhalis, Klebsiell sp, Neisseria sp. Kuman anaerob yang sering ditemukan pada abses leher dalam adalah kelompok batang gram negatif, seperti Bacteroides, Prevotella, maupun Fusobacterium. ${ }^{6}$

Adapun salah satu penelitian yang telah dilakukan Di Bagian THT-KL Rumah Sakit dr. M. Djamil Padang, periode April 2010 sampai dengan Oktober 2010 terdapat sebanyak 22 pasien abses leher dalam dan dilakukan kultur kuman penyebab, didapatkan 73\% spesimen tumbuh kuman aerob, 27\% tidak tumbuh kuman aerob dan 9\% tumbuh jamur yaitu Candida $s p .^{6}$

Berdasarkan hasil penelitian data mengenai komplikasi abses submandibula di RSU Prof. DR. R.D Kandou Manao, pada periode juni 2009 sampai juli 20012 yaitu diabetes militus hanya ditemukan 3 pasien. Hal ini terjadi karena kurangnya kelengkapan data. Namun penelitian lain yang telah dilakukan di Treviso Regional Hospital, Italy dari 81 pasien terdapat 5 pasien dengan komplikasi diabetes militus dan 1 pasien komplikasi trismus.

\section{KESIMPULAN}

Dari hasil penelitian secara retrospektif deskriptif di Bagian Bedah RSU Prof. DR. R.D. Kandou Manado periode yaitu dari Juni 2009 sampai Juli 2012, didapatkan data mengenai profil Abses Submandibula di Bagian Bedah RSU Prof. DR. R.D. Kandou Manado periode yaitu dari Juni 2009 sampai Juli 2012 adalah Penderita Abses Submandibula terbanyak merupakan penderita berjenis kelamin pria 21 orang penderita (53\%). Penderita Abses Submandibula terbanyak terdapat pada kelompok umur $>50$ (33\%). Penderita Abses Submandibula terbanyak yang diberikan perawatan yaitu Rawat Inap sebanyak 24 orang penderita (62\%). Penderita Abses Submandibula terbanyak yang diberikan tindakan yaitu nonoperatif 22 orang penderita (56\%).

\section{UCAPAN TERIMA KASIH}

Ditujukan kepada dr. Nico Lumintang, $\mathrm{SpB}(\mathrm{K}) \mathrm{KL}$ selaku Dosen Pembimbing dan Penguji I, dr. Hilman Limpeleh, SpB selaku Dosen Pembimbing II, dr. M.A. Merung, SpB(K)ONK selaku Penguji II, dan dr. Ainun Aschorijanto, SpU selaku Penguji III serta kepada semua pihak yang baik secara langsung dan tidak langsung telah menumbuhkan ide atau gagasan pada penulis sehingga penulis dapat menyelesaikan artikel ini.

\section{DAFTAR PUSTAKA}

1. Fachruddin D. Abses Leher Dalam. Dalam: Soepardi EA, Iskandar N, Bashiruddin J eds. Buku Ajar Ilmu Kesehatan Telinga Hidung Tenggorokan Kepala \& Leher. Edisi ke-6. Jakarta: Balai Penerbit FKUI; 2007. Hal 226-30.

2. Ardehali MM, Jafari M, Haqh AB. Submandibular space abscess: a clinical trial for testing a new technique. Cited 2012 Oct 7. Available from: www.ncbi.nml.nih.gov/pubmed/22267495\#.

3. A Mazita, MBBCh BaO, MYS Hazim, MS ORL-HNS, MAR Megant Shiraz MS ORL-HNS, S H A Primuharsa Putra, MS ORL-HNS.Neck Abscess: Five Year Retrospective Review of Hospital University Kebangsaan Malaysia Experience. Med J Malaysia. 2006;61(2). 
4. Ariji Y, Gotoh M, Kimura Y, Naitoh K, Kurita K, Natsume N, et al. Ondotogenic infection pathway to the submandibular space: inaging assessment. Int. J. Oral Maxillofac Surg. 2002;31:165-9.

5. Scott BA, Steinberg CM, Driscoll BP. Infection of the deep Space of the neck. In: Bailley BJ, Jhonson JT, Kohut RI et al editors. Otolaryngology Head and neck surgery. Philadelphia: JB.Lippincott Company; 2001. p. 701-15.

6. Huang T, chen T, Rong P, Tseng F, Yeah T, Shyang C. Deep neck infection:analysis of 18 cases. Head and neck; 2004. p. 860-4.

7. Pulungan MR. Pola Kuman abses leher dalam. Diunduh dari http://www.scribd.com/doc/48074146/POLA-KUMAN-ABSES-LEHER-DALAMRevisi. [Diakses tanggal 7 oktober 2012].

8. Rambe AYM. Abses Retrofaring. Fakultas kedokteran Bagian Ilmu PenyakitTelinga Hidung Tenggorokan Universitas Sumatra Utara. Diunduh dari USUdigital library 2003. [Diakses tanggal 7 oktober 2012]. 